CLINICAL STUDY

\title{
Non-functioning pituitary adenoma database: a useful resource to improve the clinical management of pituitary tumors
}

\author{
Emanuele Ferrante, Monica Ferraroni ${ }^{1}$, Tristana Castrignanò ${ }^{2}$, Laura Menicatti ${ }^{3}$, Mascia Anagni ${ }^{4}$, \\ Giuseppe Reimondo ${ }^{5}$, Patrizia Del Monte ${ }^{6}$, Donatella Bernasconi ${ }^{6}$, Paola Loli ${ }^{3}$, Marco Faustini-Fustini ${ }^{4}$, \\ Giorgio Borretta ${ }^{7}$, Massimo Terzolo ${ }^{5}$, Marco Losa ${ }^{2}$, Alberto Morabito ${ }^{1}$, Anna Spada, Paolo Beck-Peccoz \\ and Andrea G Lania \\ Endocrinology Unit, Department of Medical Sciences, University of Milan, Fondazione IRCCS Ospedale Maggiore, Policlinico, Mangiagalli e Regina Elena, \\ Via F Sforza, 35, 20122 Milano, Italy, ${ }^{1}$ Department of Medicine, Surgery and Dentistry, Unit of Medical Statistics, University of Milan, Milan, Italy, \\ ${ }^{2}$ Pituitary Unit, Department of Neurosurgery, Istituto Scientifico San Raffaele, Universita Vita-Salute, Milano, Italy, ${ }^{3}$ Division of Endocrinology, Niguarda \\ Hospital, Milan, Italy, ${ }^{4}$ Division of Endocrinology, Bellaria Hospital, 40139 Bologna, Italy, ${ }^{5}$ Division of Internal Medicine, University of Turin, Azienda \\ Sanitaria Ospedaliera San Luigi, Regione Gonzole 10, 10043 Orbassano, Italy, ${ }^{6}$ Division of Endocrinology, Galliera Hospital, 16128 Genova, Italy and \\ ${ }^{7}$ Division of Endocrinology, Santa Croce e Carle Hospital, Cuneo, Italy \\ (Correspondence should be addressed to A Lania; Email: andrea.lania@unimi.it)
}

\begin{abstract}
Objective: The long-term outcome of non-functioning pituitary adenoma (NFPA) patients is not clearly established, probably due to the low annual incidence and prolonged natural history of these rare tumors. The aim of this study was to evaluate clinical data at presentation and long-term post-surgery and radiotherapy outcome in a cohort of patients with NFPA.

Design and methods: A computerized database was developed using Access 2000 software (Microsoft Corporation, 1999). Retrospective registration of 295 NFPA patients was performed in seven Endocrinological Centers of North West Italy. Data were analyzed by STATA software.

Results: The main presenting symptoms were visual defects $(67.8 \%)$ and headache $(41.4 \%)$ and the most frequent pituitary deficit was hypogonadism (43.3\%), since almost all tumors were macroadenomas $(96.5 \%)$. Surgery was the first choice treatment (98\% of patients) and total debulking was achieved in $35.5 \%$. Radiotherapy was performed as adjuvant therapy after surgery in $41 \%$ of patients. At the followup, recurrence occurred in $19.2 \%$ of patients without post-surgical residual tumor after $7.5 \pm 2.6$ years, regrowth in $58.4 \%$ of patients with post-surgical remnant after $5.3 \pm 4.0$ years and residue enlargement in $18.4 \%$ of patients post-surgically treated with radiotherapy after $8.1 \pm 7.3$ years.

Conclusions: Our database indicates that the goal of a definitive surgical cure has been achieved during the last decade in a low percentage of patients with NFPA. This tumor database may help to reduce the delay between symptom onset and diagnosis, to assess prognostic parameters for the follow-up of patients with different risk of recurrence and to define the efficacy and safety of different treatments and their association with mortality/morbidity.
\end{abstract}

European Journal of Endocrinology 155 823-829

\section{Introduction}

Non-functioning pituitary adenomas (NFPAs) are the most frequent type of pituitary tumors. Because of hormonal inactivity, patients bearing this tumor type often present with macroadenomas that cause neurological symptoms due to mass effects. Neurosurgery, by the transsphenoidal approach whenever possible, is the treatment of choice of NFPAs. However, given the frequent supra- or parasellar extension, surgical therapy is infrequently curative, leaving tumor remnants that regrow during long-term follow-up in a significant proportion of cases $(1,2)$. In this context, the use of post-operative radiotherapy is still controversial. Despite the demonstrated efficacy of radiotherapy in preventing tumor regrowth $(3,4)$, the selection of patients who will benefit by this therapy is made difficult by the absence of specific markers of tumor aggressiveness along with the potential side effects of this procedure that include hypopituitarism, neurocognitive dysfunction and development of secondary intracranial tumor $(2,5,6)$. As far as the medical therapy is concerned, the use of dopamine agonists and/or somatostatin analogs has been proposed, given the expression of both dopamine and somatostatin receptors in NFPAs (7-10). However, available data show that the efficacy of these agents as first choice treatment is negligible (11-15).

Since the long-term outcome of NFPA patients is not clearly established, probably due to the low annual 
incidence and prolonged natural history of these rare tumors, we developed a computerized database to collect clinical, biochemical, radiological, ophthalmological, and outcome data of patients referred to seven Endocrinological Centers in North West Italy for diagnosis, cure and follow-up of NFPAs. Results obtained from our database indicate that the goal of a definitive surgical cure has been only partially achieved in Italy during the last decade. These data should challenge endocrinologists and general practitioners to entertain early diagnosis of these insidious and slow-growing tumors.

\section{Materials and methods}

\section{Patients}

This retrospective registration took place between January 12004 and December 312004 in seven Endocrinological Centers of major teaching and general hospitals that represent highly qualified centers for diagnosis and treatment of pituitary tumors in the North-west Italian area. The protocol was approved by the local ethical committee of each hospital. Each medical record was relative to a patient with confirmed NFPA, diagnosed and followed in one of the participating centers subsequently to 1976. Clinical, biochemical, radiological, ophthalmological, and outcome data from 295 patients with NFPA were registered. Diagnosis of NFPA was based on the presence of a sellar lesion in the absence of hormonal hypersecretion and confirmed at histological examination of the surgically removed tissues. All patients performed computed tomography (CT) scan or magnetic resonance imaging (MRI). Immunohistochemical findings were available in a minority of tumors.

Tumor regrowth was investigated in 226 patients, after the exclusion of patients without a careful description of neuroradiological findings before and/or after therapeutical procedures, patients with radiological modifications occurred in concomitance with a change of imaging techniques and patients with a follow-up $<5$ years $(n=69)$. On the basis of first postoperative imaging and the following therapeutical approach, patients were classified as follows: group A, patients with no neuroradiological evidence of residual tumor; group B, patients with post-operative tumor remnant who did not undergo radiation therapy; group $\mathrm{C}$, patients with post-operative tumor remnant who were treated with radiotherapy after surgery.

\section{Non-functioning pituitary adenoma database}

An evidence-based computerized pituitary tumor database was developed using Access 2000 software (Microsoft Corporation, 1999). The choice of specific fields was made to obtain a large and complete overview of patients with NFPA, including risk factors, associated diseases, signs and symptoms as well as hormonal, neuroradiological, visual, and therapeutical data. The database was divided into two parts: a principal record, including information about the patient at the time of recruitment, and several follow-up records. Each patient received an identification number, and personal information was available only to principal investigators or co-investigators.

Periodic meetings were organized in order to make the recording process as homogeneous as possible for all centers. A manual procedure was developed, with detailed instructions and definitions needed for a correct compilation of the database. A copy of the structure of the database is available on request.

\section{Diagnostic criteria}

A preliminary meeting of the principal investigators from each center was organized to select the clinical, biochemical, radiological, ophthalmological, and outcome parameters to be included in the database and to assess their definition. Tumor size was determined by CT scan or MRI of the sellar region. Tumors $<10 \mathrm{~mm}$ diameter were defined microadenomas and equal or greater than $10 \mathrm{~mm}$ macroadenomas. Depending on the information available in the principal record about neuroradiological characteristics of tumor (micro/macroadenoma, cavernous sinus invasion, sphenoid sinus invasion, optic chiasm compression, and stalk dislocation), adenomas were arbitrarily classified into grades I, II, III, and IV, indicating microadenoma, non-invasive macroadenoma, macroadenoma with invasion of one surrounding structure, and macroadenoma with invasion of two or more surrounding structures respectively. Central hypothyroidism was defined as low FT4 levels in the presence of inappropriate thyroid-stimulating hormone (TSH) levels. Central hypoadrenalism was defined as a lack of response to stimulation tests (peak cortisol levels lower than $500 \mathrm{nmol} / \mathrm{l}$ during $1 \mu \mathrm{g}$ adrenocorticotrophic hormone (ACTH) test or insulin tolerance test). Central hypogonadism was diagnosed in the presence of low estradiol or testosterone levels and inappropriately normal or low gonadotropin levels. Growth hormone (GH) deficiency was diagnosed in the absence of adequate response to stimulation tests (peak GH levels lower than 3 or $9 \mu \mathrm{g} / \mathrm{l}$ after insulin tolerance test or growth hormone-releasing hormone $(\mathrm{GHRH})+$ arginine test respectively). Concomitant hyperprolactinemia was defined as prolactin (PRL) levels above the normal range and not consistent with the diagnosis of PRL-secreting adenoma. Hormonal values were interpreted according to the normal range of each laboratory.

Radiographic cure was defined as the absence of clear tumor remnants on the first post-operative (MRI) or (CT, if MRI scans were not available). Recurrence was defined as a detection of pituitary tumor in patients without evidence of residual tumor after surgical therapy, while regrowth was defined as an enlargement of tumor remnant at post-operative imaging. 


\section{Statistical analysis}

All the quantitative variables are shown as mean \pm s.D. given the skewness of all variables time at the event, the comparison between different categories was made with Kruskal-Wallis test (16). The association between extension or grade of tumor and gender were studied using $\chi^{2}$ - or the Fisher's test for categorical variables (16). Analysis of cumulative incidence of recurrence or regrowth was made with Kaplan-Meier method, and differences among groups were tested with log-rank test. In all groups, the time from the surgery and the first recurrence or regrowth for elapsed patients and time from the surgery and the last follow-up for unelapsed patients were calculated. All the data analysis was made in STATA8 (StataCorp LP).

\section{Results}

Patients population, symptoms, and hormonal alterations

In the database, 295 patients (161 men/134 women) with a mean age of $50.4 \pm 14.1$ years (range 14-78 years) and a mean time of follow-up of $5.7 \pm 4.3$ years (range 2-28 years) were registered. No significant differences in the age at diagnosis $(P=\mathrm{NS})$, time of follow-up $(P=N S)$ and number of visits during the follow-up $(P=\mathrm{NS}$ ) between men and women were found. The diagnosis of NFPA was more frequently performed during the sixth decade of age for men and the fifth decade for women (Fig. 1).

Table 1 shows symptoms, hormonal alterations, neuroradiological, and visual findings at the time of diagnosis.

Most frequently, NFPA patients reported massrelated symptoms, such as visual deficit (67.8\%) and headache $(41.4 \%)$. Hypogonadal symptoms (i.e. loss of libido, impotence, oligo-amenorrhea) were observed in $42.5 \%$ of female and in $37.9 \%$ of male patients respectively (Table 1). At presentation, isolated or multiple pituitary deficits were diagnosed in $62 \%$ of patients. In particular, hypogonadism was the most frequent deficit reported $(43.3 \%)$ and diabetes insipidus the rarest $(1.9 \%)$ (Table 1). Concomitant

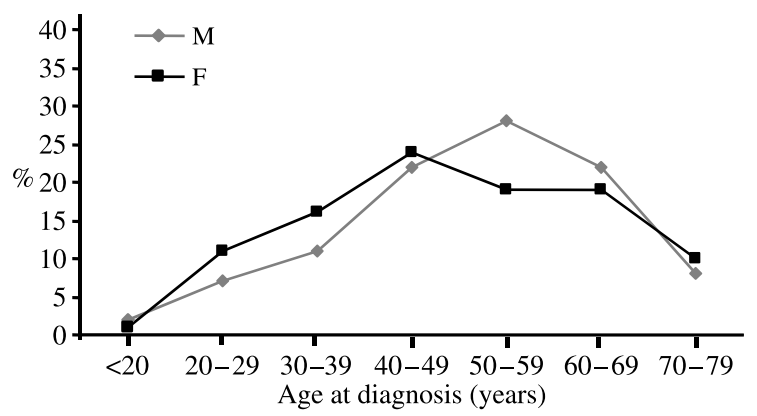

Figure 1 Percentage distribution of age (decades) in non-functioning pituitary adenoma patients at the time of diagnosis $(n=295)$.
Table 1 Symptoms, hormonal alterations, neuroradiological and visual findings in 295 patients with non-functioning pituitary adenomas at the time of diagnosis.

$\%$ of patients

\begin{tabular}{lc}
\hline Symptoms & \\
Visual deficit & 67.8 \\
Headache & 41.4 \\
Asthenia & 26.4 \\
Loss of libido & 28(M); $9.7(\mathrm{~F})$ \\
Menstrual disorders & 32.8 \\
Galactorrhea & 7.8 \\
Impotence & 9.9 \\
Hormonal alterations & \\
Hypogonadism & \\
GH deficiency & 43.3 \\
Hyperprolactinemia & 35.8 \\
Hypoadrenalism & 27.6 \\
Hypothyroidism & 26.2 \\
Diabetes insipidus & 24.5 \\
Neuroradiological findings & 1.9 \\
Optic chiasm compression & \\
Cavernous sinus invasion & 45.4 \\
Sphenoid sinus invasion & 33.2 \\
Stalk dislocation & 14.2 \\
Grade & 12.2 \\
I & \\
II & 3.4 \\
III & 33.9 \\
IV & 30.8 \\
Casual findings & 31.9 \\
Campimetric alterations (right eye) & \\
Loss of visual acuity (right eye) & 59.7 \\
Loss of visual acuity (left eye) & 64.2 \\
\end{tabular}

$F$, female; M, male.

${ }^{a}$ Percentages were relative to the patients for which these alterations were evaluated.

${ }^{b}$, II, III, IV, indicating microadenoma, non-invasive macroadenoma, macroadenoma with invasion of one surrounding structure, and macroadenoma with invasion of two or more surrounding structures respectively.

hyperprolactinemia was encountered in $27.6 \%$ of patients. No relationship between the presentation of the disease and the decade in which diagnosis occurred was observed (data not shown).

\section{Neuroradiological and visual findings}

Tumor extension was determined by CT scan or MRI. A macroadenoma was present in $96.5 \%$ of patients, causing optic chiasm compression and cavernous sinus invasion in a significant proportion of patients (45.4 and $33.2 \%$ respectively), without significant gender difference (Table 1). Tumors were equally distributed across grade II, III, and IV without significant sex-related differences $(P=N S)$. No relationship between the size and the invasiveness of the tumors and the decade in which diagnosis occurred was observed (data not shown).

Study of visual field was performed in 240/295 patients $(81.4 \%)$. Visual field alterations were observed in the majority of patients and impairment of visual acuity in about one-third (Table 1). 


\section{Therapy and outcome}

In all centers, the first choice treatment was neurosurgery performed in $268 / 295$ patients $(90.8 \%$ ). The transsphenoidal route was performed in $89 \%$ of cases, while the remaining patients were treated by the transcranial approach. After a mean period of $2.8 \pm$ 2.9 years, 22 out of 27 patients, who initially received medical treatment with somatostatin analogs or had no treatment, were subsequently surgically treated. Therefore, 290/295 (98\%) patients underwent surgery. On the basis of radiological findings, 105 surgically treated patients $(35.5 \%)$ were considered cured (total tumor debulking). After a mean time of $5.2 \pm 4.7$ years, 80 patients underwent one or more additional surgical treatments (Fig. 2).

Radiotherapy was performed in 121 patients (41\%). In all the cases, radiotherapy was used as adjuvant therapy after surgery. After a mean time of $3.5 \pm 3.3$ years, 32 out of 121 patients were treated at entrance into our centers, while the remaining 89 were treated subsequently. The distribution of the total number of surgical and radiotherapeutic treatments in 295 NFPA patients is summarized in Fig. 2.

\section{Tumor recurrence or regrowth}

Tumor recurrence or regrowth was investigated in 226 patients with a minimum follow-up of 5 years (mean follow-up 9.3 \pm 4.3 years, range 5.1-28 years). Seventy-three patients did not show neuroradiological evidence of residual tumor after surgical therapy (group A), 77 patients showed a post-operative tumor remnant, but did not undergo radiation therapy (group B) and 76 patients, with evidence of tumor remnant, were treated with radiotherapy after surgery (group C) (Fig. 3). Recurrence occurred in 14 out of 73 patients of group A (19.2\%) after a mean period of

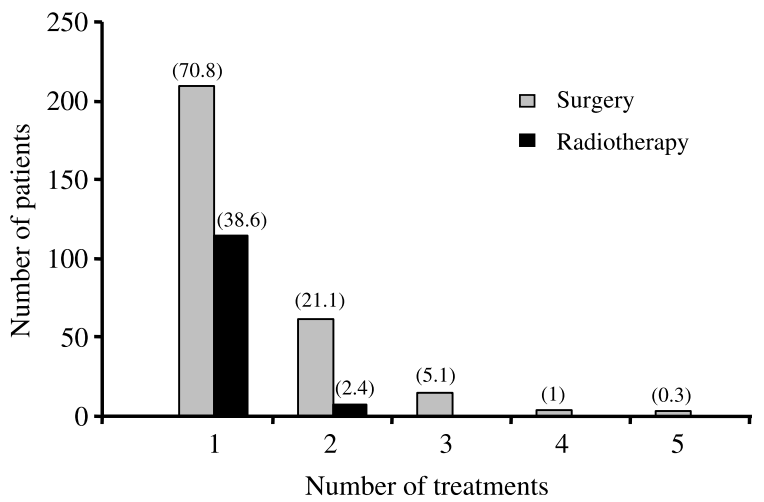

Figure 2 Distribution of the total number of surgical or radiotherapical treatments in non-functioning pituitary adenoma patients $(n=295)$. The percentage of patients who underwent surgery or radiotherapy is indicated in parentheses.

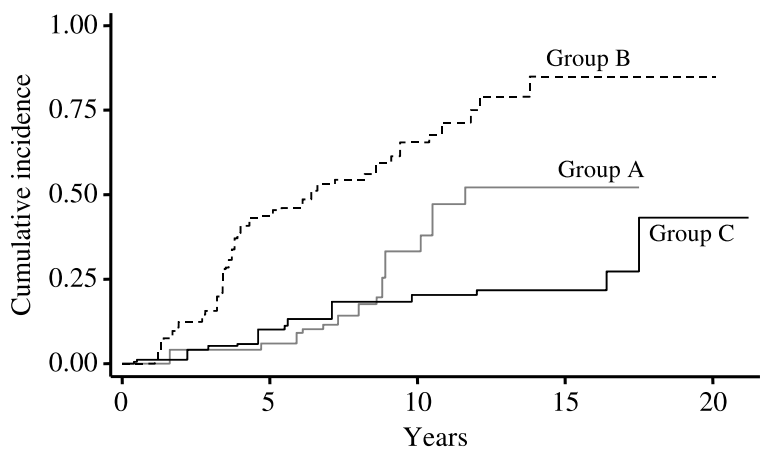

Figure 3 Cumulative incidence of recurrence or regrowth patients with non-functioning pituitary adenomas $(n=226)$. A indicates patients without postoperative tumor treatment, $B$, patients with tumor remnant who did not receive radiotherapy and $\mathrm{C}$, patients with residual tumor treated with radiotherapy. The difference in the probability of recurrence or regrowth between the three groups was significantly different (Log-rank=119.83, $\mathrm{df}=2, P>0.0001)$, but with no difference between groups $A$ and $C$ (Log-rank=2.25, $\mathrm{df}=1, P=\mathrm{NS})$.

$7.5 \pm 2.6$ years (range 1.6-11.6 years), tumor regrowth in 45 out of 77 patients of group B (58.4\%) after a mean period of $5.3 \pm 4.0$ years (range $1.1-20.3$ years), and in 14 out of $76(18.4 \%)$ patients of group C after a mean period of $8.1 \pm 7.3$ years (range $0.4-25.5$ years). Analysis of cumulative incidence showed a significant difference in the probability of recurrence or regrowth among three groups (log-rank $=119.83, \mathrm{df}=2, \mathrm{P}<$ 0.0001), with no difference between group $\mathrm{A}$ and $\mathrm{C}$ $(\log -\mathrm{rank}=2.25, \mathrm{df}=1, P=\mathrm{NS}$; Fig. 3). Collectively, tumor regrowth of group $B$ patients peaked after a time interval of $<5$ years, recurrence of group A patients after a 5-10 years interval, while tumor enlargement after radiotherapy in group $\mathrm{C}$ occurred equally across the follow-up period (Fig. 4).

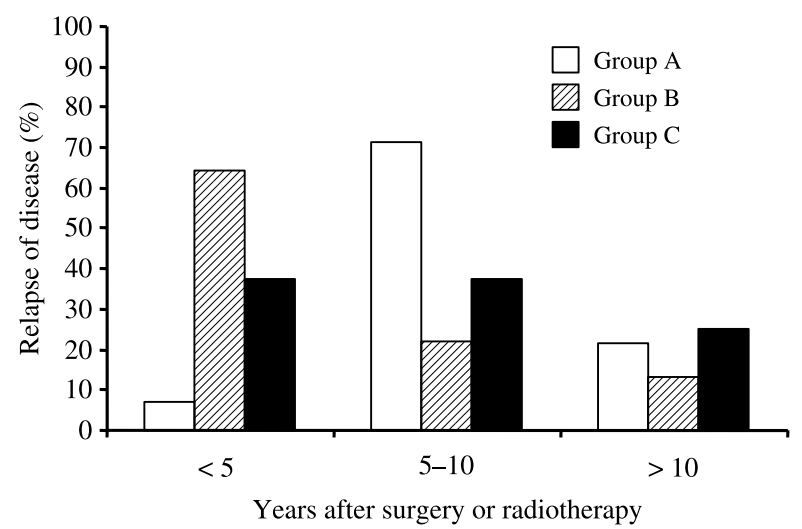

Figure 4 Time distribution of percentage of tumor recurrence or regrowth in patients with non-functioning pituitary adenoma $(n=226)$. A indicates patients without postoperative tumor treatment, B, patients with tumor remnant who did not receive radiotherapy and $\mathrm{C}$, patients with residual tumor treated with radiotherapy. 


\section{Discussion}

This is the first reported database that collected clinical, biochemical, radiological, ophthalmological, and outcome data specifically focused on NFPAs in Europe. The aim of this database was to provide retrospective information on demographic, clinical and biochemical presentation, therapeutic approaches, and long-term outcomes in patients with NFPA. The ultimate goal is to improve the management of these tumors. Admittedly, since most the centers participating in this project were centers of major teaching and general hospitals and most patients were referrals from other specialists, it is conceivable that the registered data might be pertinent to patients with more complex diseases and not to the overall population of NFPAs. Analysis of the registered data (i.e. the tumor size, the symptoms due to the mass effect and the similar presentation of the disease over time) indicated a dramatic delay in the diagnosis of NFPA, despite the improvement of the currently available biochemical and neuroradiological techniques. In fact, almost all the patients of our series harbored macroadenomas that were mainly diagnosed between the fifth and the seventh decade. Moreover, invasion of the surrounding structures was present at diagnosis in two-third of patients. These data are consistent with many reports $(1,3-5,17)$, but partially in contrast to the information collected in the only other available pituitary tumor registry in US, reporting that age at diagnosis of NFPAs peaked across the fourth and the fifth decade and showing a higher prevalence of microadenomas (32\%) in women (18). NFPAs presented in about half of the patients with mass-related symptoms, as visual defects, headache, and hypogonadism symptoms. Unfortunately, these signs are still underestimated or not correctly diagnosed, especially considering the mean age of patients at diagnosis. Therefore, the reduction of the delay between symptom onset and diagnosis still represents a challenge for endocrinologists, gynecologists, andrologists, ophthalmologists and, particularly, general practitioners.

One-fourth of patients had mild hyperprolactinemia, typically related to stalk deafferentation, while single or multiple pituitary deficits were diagnosed in $62 \%$ of patients before surgery, in agreement with previous reports $(5,18,19)$. Admittedly, the percentage of patients with pituitary deficit was probably underestimated because some functions, in particular GH secretion, were not routinely evaluated in the past.

As expected, surgery represented the first therapeutical approach. Radiological cure, defined as the absence of tumor remnants on neuroradiological imaging, was achieved in $35.5 \%$ of patients. This result, that is in agreement with previous studies $(4,5,18)$, was related to the large size of almost all NFPAs at diagnosis. Moreover, it is worth noting that about onethird of not cured patients in our database underwent one or more additional surgical treatments. Failure of surgical treatment caused a frequent indication for conventional or stereotactic radiotherapy that was performed in about $40 \%$ of patients. However, the role of conventional radiotherapy in pituitary tumor management remains controversial. Although its efficacy in reducing recurrence or regrowth of tumor remnants, in particular if administered during postoperative period, has been demonstrated $(1,3,6)$, this therapy may cause several side effects, as hypopituitarism, increased risk of second brain tumor, neurocognitive, or neuropsychological impairments (20-23). New radiation techniques, such as Gamma Knife radiosurgery, have shown in the short-term to have a good efficacy in controlling tumor growth and a more favorable profile of side effects than conventional fractionated radiotherapy $(24,25)$.

As far as the long-term outcomes of patients registered in our database were concerned, patients without postoperative residual tumor and patients who underwent adjuvant radiotherapy showed a similar risk of tumor recurrence or regrowth (reported in 19.2 and 18.4\% respectively), while tumor remnant regrew in $58.4 \%$ of patients who did not receive radiotherapy. These data are in agreement with previous reports $(1,2,5,26,27)$. Some interesting information arises from the different time of occurrence of regrowth or recurrence. In particular, tumor enlargement after radiotherapy occurred all along across the follow-up periods, while recurrence in cured patients peaked after 5-10 years from surgery. These data suggest that a close follow-up, with serial MRI every 12 18 months, is necessary for at least 10 years in all patients, followed by a follow-up based on clinical indications. In this respect, administration of dopamine agonists associated or not with octreotide analogs has been proposed as adjuvant treatment for patients with NFPAs unsuccessfully treated by surgery (28-30).

Patients with NFPAs have an increased mortality, mainly due to respiratory, cardiovascular, and cerebrovascular diseases, that seems to be related to several factors, including surgery, untreated hypopituitarism, and radiotherapy (31-38). Our database clearly indicates that the goal of a definitive surgical cure, without subsequent radiotherapy and with preservation of normal residual pituitary functions, has been achieved during the last decade in a low percentage of patients, even when followed in highly qualified endocrine centers.

In conclusion, data collected in our database give a complete overview of patients with NFPA in term of clinical debut, therapeutic approaches, and longterm outcomes. This tumor database may help to reduce the delay between symptom onset and diagnosis, to assess prognostic parameters for the follow-up of patients with different risk of recurrence and to define the efficacy and safety of different treatments and their association with mortality/ morbidity. Moreover, the relatively large number of cases recorded in our database may be used prospectively to evaluate clinical and diagnostic 
progresses and to improve therapeutic guidelines and overall cost-effectiveness in the long-term management of NFPAs.

\section{Acknowledgements}

The present work was partially supported by FIRST, Fondazione Ospedale Maggiore IRCCS and Associazione Italiana per la Ricerca sul Cancro AIRC (Milan).

\section{References}

1 Turner HE, Stratton IM, Byrne JV, Adams CB \& Wass JA. Audit of selected patients with nonfunctioning pituitary adenomas treated without irradiation - a follow-up study. Clinical Endocrinology $199951281-284$

2 Boelaert K \& Gittoes NJ. Radiotherapy for non-functioning pituitary adenomas. European Journal of Endocrinology 2001144 569-575.

3 Gittoes NJ, Bates AS, Tse W, Bullivant B, Sheppard MC, Clayton RN \& Stewart PM. Radiotherapy for non-function pituitary tumours. Clinical Endocrinology 199848 331-337.

4 Woollons AC, Hunn MK, Rajapakse YR, Toomath R, Hamilton DA, Conaglen JV \& Balakrishnan V. Non-functioning pituitary adenomas: indications for postoperative radiotherapy. Clinical Endocrinology 200053 713-717.

5 Greenman Y, Ouaknine G, Veshchev I, Reider-Groswasser II, Segev Y \& Stem N. Postoperative surveillance of clinically nonfunctioning pituitary macroadenomas: markers of tumour quiescence and regrowth. Clinical Endocrinology $2003 \mathbf{5 8} 763-769$.

6 Gittoes NJ. Radiotherapy for non-functioning pituitary tumourswhen and under what circumstances? Pituitary 20036 103-108.

7 Panetta R \& Patel YC. Expression of mRNA for all five human somatostatin receptors (hSSTR1-5) in pituitary tumours. Life Science 199556 333-342.

8 Nielsen S, Mellemkjaer S, Rasmussen LM, Ledet T, Astrup J, Weeke J \& Jorgensen JO. Gene transcription of receptors for growth hormonereleasing peptide and somatostatin in human pituitary adenomas. Journal of Clinical Endocrinology and Metabolism 199883 2997-3000.

9 de Herder WW, Reijs AE, de Swart J, Kaandorp Y, Lamberts SW, Krenning EP \& Kwekkeboom DJ. Comparison of iodine-123 epidepride and iodine-123 IBZM for dopamine D2 receptor imaging in clinically non-functioning pituitary macroadenomas and macroprolactinomas. European Journal of Nuclear Medicine 199926 46-50.

10 Nielsen S, Mellemkjaer S, Rasmussen LM, Ledet T, Olsen N. BojsenMoller M, Astrup J, Weeke J \& Jorgensen JO. Expression of somatostatin receptors on human pituitary adenomas in vivo and ex vivo. Journal of Endocrinological Investigation 200124 430-437.

11 Katznelson L, Oppenheim DS, Coughlin JF, Kliman B, Schoenfeld DA \& Klibanski A. Chronic somatostatin analog administration in patients with alpha-subunit-secreting pituitary tumours. Journal of Clinical Endocrinology and Metabolism 199275 1318-1325.

12 de Bruin TW, Kwekkeboom DJ, Van't Verlaat JW, Reubi JC, Krenning EP, Lamberts SW \& Croughs RJ. Clinically nonfunctioning pituitary adenoma and octreotide response to long term high dose treatment, and studies in vitro. Journal of Clinical Endocrinology and Metabolism 199275 1310-1317.

13 Gasperi M, Petrini L, Pilosu R, Nardi M, Marcello A, Mastio F, Bartalena L \& Martino E. Octreotide treatment does not affect the size of most non-functioning pituitary adenomas. Journal of Endocrinological Investigation 199316 541-543.

14 Merola B, Colao A, Ferone D, Selleri A, Di Sarno A, Marzullo P, Biondi B, Spaziante R, Rossi E \& Lombardi G. Effects of a chronic treatment with octreotide in patients with functionless pituitary adenomas. Hormone Research 199340 149-155.

15 Andersen M, Bjerre P, Schroder HD, Edal A, Hoilund-Carlsen PF, Pedersen PH \& Hagen C. In vivo secretory potential and the effect of combination therapy with octreotide and cabergoline in patients with clinically non-functioning pituitary adenomas. Clinical Endocrinology $20015423-30$.

16 Snedecor GW \& Cochran WG. Statistical Methods. 8th edn, Ames, Iowa: Iowa State University Press, 1989.

17 Erfurth EM, Bulow B, Nordstrom CH, Mikoczy Z, Hagmar L \& Stromberg U. Doubled mortality rate in irradiated patients reoperated for regrowth of a macroadenoma of the pituitary gland. European Journal of Endocrinology 2004150 497-502.

18 Drange MR, Fram NR, Herman-Bonert V \& Melmed S. Pituitary tumour registry: a novel clinical resource. Journal of Clinical Endocrinology and Metabolism 200085 168-174.

19 Bates AS, Bullivant B, Sheppard MC \& Stewart PM. Life expectancy following surgery for pituitary tumours. Clinical Endocrinology $199950315-319$.

20 Littley MD, Shalet SM, Beardwell CG, Ahmed SR, Applegate G \& Sutton ML. Hypopituitarism following external radiotherapy for pituitary tumours in adults. Quarterly Journal of Medicine 198970 145-160.

21 Brada M, Ford D, Ashley S, Bliss JM, Crowley S, Mason M, Rajan B \& Traish D. Risk of second brain tumour after conservative surgery and radiotherapy for pituitary adenoma. British Medical Journal 199223 1343-1346.

22 Tsang RW, Laperriere NJ, Simpson WJ, Brierley J, Panzarella T \& Smyth HS. Glioma arising after radiation therapy for pituitary adenoma. A report of four patients and estimation of risk. Cancer 199372 2227-2233.

23 McCord MW, Buatti JM, Fennell EM, Mendenhall WM, Marcus RB Jr, Rhoton AL, Grant MB \& Friedman WA. Radiotherapy for pituitary adenoma: long-term outcome and sequelae. International Journal of Radiation Oncology Biology Physics 199739 437-444.

24 Sheehan JP, Kondziolka D, Flickinger J \& Lunsford LD. Radiosurgery for residual or recurrent nonfunctioning pituitary adenoma. Journal of Neurosurgery 200297 408-414.

25 Losa M, Valle M, Mortini P, Franzin A, da Passano CF, Cenzato M, Bianchi S, Picozzi P \& Giovanelli M. Gamma knife surgery for treatment of residual nonfunctioning pituitary adenomas after surgical debulking. Journal of Neurosurgery 2004100 438-444.

26 Bradley KM, Adams CB, Potter CP, Wheeler DW, Anslow PJ \& Burke CW. An audit of selected patients with non-functioning pituitary adenoma treated by transsphenoidal surgery without irradiation. Clinical Endocrinology 199441 655-659.

27 Lillehei KO, Kirschman DL, Kleinschmidt-DeMasters BK \& Ridgway EC. Reassessment of the role of radiation therapy in the treatment of endocrine-inactive pituitary macroadenomas. Neurosurgery $1998 \mathbf{4 3}$ 432-438.

28 Andersen M, Bjerre P, Schroder HD, Edal A, Hoilund-Carlsen PF, Pedersen PH \& Hagen C. In vivo secretory potential and the effect of combination therapy with octreotide and cabergoline in patients with clinically non-functioning pituitary adenomas. Clinical Endocrinology 200154 23-30.

29 Pivonello R, Matrone C, Filippella M, Cavallo LM, Di Somma C, Cappabianca P, Colao A, Annunziato L \& Lombardi G. Dopamine receptor expression and function in clinically nonfunctioning pituitary tumours: comparison with the effectiveness of cabergoline treatment. Journal of Clinical Endocrinology and Metabolism 200489 1674-1683.

30 Greenman Y, Tordjman K, Osher E, Veshchev I, Shenkerman G, Reider-roswasser II, Segev Y, Ouaknine G \& Stern N. Postoperative treatment of clinically nonfunctioning pituitary adenomas with dopamine agonists decreases tumour remnant growth. Clinical Endocrinology 200563 39-44.

31 Rosen T \& Bengtsson BA. Premature mortality due to cardiovascular disease in hypopituitarism. Lancet 1990336 285-288.

32 Bates AS, Van't Hoff W, Jones PJ \& Clayton RN. The effect of hypopituitarism on life expectancy. Journal of Clinical Endocrinology and Metabolism 199681 1169-1172.

33 Bulow B, Hagmar L, Mikoczy Z, Nordstrom CH \& Erfurth EM. Increased cerebrovascular mortality in patients with hypopituitarism. Clinical Endocrinology 199746 75-81. 
34 Clayton RN. Mortality, cardiovascular events and risk factors in hypopituitarism. Growth Hormone and IGF Research 1998 8 69-76.

35 Nilsson B, Gustavasson-Kadaka E, Bengtsson BA \& Jonsson B. Pituitary adenomas in Sweden between 1958 and 1991: incidence, survival, and mortality. Journal of Clinical Endocrinology and Metabolism 200085 1420-1425.

36 Tomlinson JW, Holden N, Hills RK, Wheatley K, Clayton RN, Bates AS, Sheppard MC \& Stewart PM. Association between premature mortality and hypopituitarism. West Midlands Prospective Hypopituitary Study Group. Lancet 2001357 425-431.

37 Erfurth EM, Bulow B, Svahn-Tapper G, Norrving B, Odh K, Mikoczy Z, Bjork J \& Hagmar L. Risk factors for cerebrovascular deaths in patients operated and irradiated for pituitary tumours. Journal of Clinical Endocrinology and Metabolism 2002 87 4892-4899.

38 Brada M, Ashley S, Ford D, Traish D, Burchell L \& Rajan B. Cerebrovascular mortality in patients with pituitary adenoma. Clinical Endocrinology 200257 713-717.

Received 10 July 2006

Accepted 18 September 2006 